\title{
Leucine-rich a2-glycoprotein-1 upregulation in plasma and kidney of patients with lupus nephritis
}

\author{
Yi Yang, Ran Luo, Yichun Cheng, Tingting Liu, Wei Dai, Yueqiang Li, Shuwang Ge ${ }^{*+}$ and Gang Xu ${ }^{\dagger}$
}

\begin{abstract}
Background: Increased leucine-rich a2-glycoprotein-1 (LRG1) has been observed in various inflammatory and autoimmune diseases. We aimed to explore the expression and role of LRG1 in lupus nephritis (LN).

Methods: Plasma LRG1 (pLRG1) was measured by enzyme-linked immunosorbent assay in 101 patients with renal biopsy-proven LN and 21 healthy controls (HC). Relationships between pLRG1 and clinical and pathological characteristics were analyzed. The expression of LRG1 in peripheral blood leukocytes and kidney was detected by flow cytometry, immunohistochemistry and immunofluorescence, respectively. Further cell experiments were focused on the role of LRG1.

Results: We found that LRG1 was expressed in plasma, some peripheral blood leukocytes, proximal tubule and several inflammatory cells. The levels of LRG1 in plasma, peripheral blood leukocytes and kidney were elevated in $L N$ patients as compared to HC. Plasma expression levels of LRG1 correlated positively with renal function and renal disease activity, and reflect specific pathologic lesions in the kidneys of patients with LN. Interleukin-1 $\beta$ and interleukin-6, not tumor necrosis factor- $a$ and interferon $\gamma$ induced the LRG1 expression in human renal tubular epithelial cell line. Moreover, stimulation of recombinant human LRG1 could inhibit late apoptosis, promote proliferation and regulate expression of inflammatory factors and cytokines.
\end{abstract}

Conclusions: Plasma expression levels of LRG1 were associated with renal function, disease activity, and pathology in LN. It might also be involved in renal inflammation, proliferation and apoptosis of endothelial cells. LRG1 might be a potential prognosis novel predictor in $L N$ patients.

Keywords: Leucine-rich a2-glycoprotein-1, Lupus nephritis, Proliferation, Apoptosis, Inflammation

\section{Background}

Systemic lupus erythematosus (SLE) is a complicated and multisystem autoimmune disease [1-3]. Lupus nephritis (LN) is a serious and common manifestation of SLE, and is characterized by autoantibody-mediated activation of inflammatory response in the kidney $[2,4,5]$. About 35\% of patients show LN symptoms when SLE is

\footnotetext{
* Correspondence: geshuwang@tjh.tjmu.edu.cn

†Shuwang Ge and Gang Xu contributed equally to this work. Department of Nephrology, Tongji Hospital Affiliated with Tongji Medical College, Huazhong University of Science and Technology, 1095 Jie Fang Avenue, Wuhan, Hubei 430030, People's Republic of China
}

diagnosed and 50-60\% will develop LN during the first 10 years of disease [6,7]. Up to $26 \%$ of LN patients develop end-stage renal disease $[8,9]$. And $L N$ is a major contributor to mortality of SLE despite recent advances [3]. Hence, early diagnosis and management of $L N$ is of tremendous importance.

For LN, etiology and pathogenesis are incompletely understood. Currently, LN is gauged by proteinuria, urinary sediment, creatinine clearance, anti-doublestanded DNA antibodies and complement component with confirmation by kidney biopsies. Due to the

(c) The Author(s). 2020 Open Access This article is licensed under a Creative Commons Attribution 4.0 International License, which permits use, sharing, adaptation, distribution and reproduction in any medium or format, as long as you give appropriate credit to the original author(s) and the source, provide a link to the Creative Commons licence, and indicate if changes were made. The images or other third party material in this article are included in the article's Creative Commons licence, unless indicated otherwise in a credit line to the material. If material is not included in the article's Creative Commons licence and your intended use is not permitted by statutory regulation or exceeds the permitted use, you will need to obtain permission directly from the copyright holder. To view a copy of this licence, visit http://creativecommons.org/licenses/by/4.0/ The Creative Commons Public Domain Dedication waiver (http://creativecommons.org/publicdomain/zero/1.0/) applies to the data made available in this article, unless otherwise stated in a credit line to the data. 
invasive nature of kidney biopsies and these traditional markers are not perfect in assessing whether active LN is present or not, and none of them can anticipate the course of LN. It is of significance to explore novel sensitive and specific biomarkers of LN.

Leucine-rich alpha-2-glycoprotein 1 (LRG1) is an approximately $50-\mathrm{kDa}$ plasma glycoprotein isolated from human serum in 1977 [10]. It contains 23\% carbohydrate by weight and it consists of 312 amino acid residues, 66 of which are leucines. LRG1 has been reported to be expressed by the endothelial cells, neutrophils, macrophages and liver cells [11-13]. The precise function of LRG1 remains unknown, but accumulating evidences showed that LRG1 is closely correlated with various types of cancers, such as lung, oral, ovarian, gastrict, pancreatic and biliary tract cancers [14-18]. Moreover, LRG1 is identified as an inflammatory protein in human serum and highly expressed in various kinds of benign inflammatory and autoimmune diseases, including suspected acute appendicitis of children [19], activated ulcerative colitis [12], rheumatoid arthritis [20, 21], adultonset Still's disease [22] and asthma [23]. Especially, Ahn et al. found serum LRG, namely LRG1, is elevated in patients with SLE and correlates with disease activity [24].

We supposed that LRG1 was closely correlated with LN with the following evidences. Firstly, LN is a typical inflammatory and autoimmune disease, and LRG is elevated in patients with SLE [24]. Secondly, for kidney diseases, increased levels of LRG1 was identified in chronic kidney disease [25], sepsis patients with acute kidney injury [26], classical galactosemic patients with subclinical kidney insufficiency [27], children with idiopathic nephrotic syndrome [28] by using a plasma/serum/urine proteomics approach, but the proteomics studies just revealed a hint that LRG1 might be associated with kidney diseases. Thirdly, a mouse model of renal tubular injury indicated that LRG1 was a potential urinary biomarker [29]. Finally, Wang et al. reported that LRG1 promoted angiogenesis in endothelial cells [30]. Angiogenesis widely exists in kidney of LN. Therefore, studying roles of LRG1 in LN is a rich research area.

Thus, we conducted a study to determine positioning and compare the expression of LRG1 levels in plasma, peripheral blood leukocyte and kidney tissue in LN patients and healthy controls, to determine whether plasma LRG1 (pLRG1) was a biomarker for disease activity of LN and to explore the possible mechanisms.

\section{Methods}

\section{Patients and specimens}

A total of 101 biopsy-proven LN patients, 21 healthy controls (HC) subjects were recruited for this study. All of the patients were biopsy-proven $\mathrm{LN}$ according to the
2003 International Society of Nephrology (ISN)/Renal Pathology Society (RPS) classification criteria for LN. For the included patients, baseline clinical data at the time of renal biopsy were recorded. Venous plasma samples of LN patients at the time of renal biopsy and $\mathrm{HC}$ subjects were obtained and stored at $-80^{\circ} \mathrm{C}$ for batch analysis. Informed consent was obtained from these participants. The protocol was approved by the Ethical Committee of Tongji Hospital, which is affiliated with Tongji Medical College, Huazhong University of Science and Technology (Project No. TJ-IRB20181106).

\section{LRG1 enzyme-linked immunosorbent assay (ELISA)}

Concentrations of pLRG1 were detected using a human ELISA kit (ImmunoBiological Laboratories Co Ltd., Takasaki, Gunma, Japan) according to the manufacturer's protocol.

Flow cytometric analysis of LRG1 expression in peripheral blood leukocytes from LN patients and healthy controls To detect LRG1 expression on neutrophils (CD15+), monocytes (CD14+), NK cells (CD3- CD56+), T cells (CD3+), B cells (CD19+) in peripheral blood leukocytes, we used the following antibodies from BioLegend: phycoerythrin-conjugated (PE-conjugated) anti-human CD15 Ab; PerCP/ Cy5.5-conjugated anti-human CD14 $\mathrm{Ab}$; allophycocyanin-conjugated (APC-conjugated) antihuman CD3 Ab; BV421-conjugated anti-human CD56 $\mathrm{Ab}$; PE-conjugated anti-human CD19 Ab. In addition, we used FITC-conjugated anti-human LRG1 Ab from ASSAYPRO. Flow cytometry measurements were performed using a FACS Calibur flow cytometer (Becton Dickinson, LSRII).

\section{Immunohistochemistry (IHC)}

IHC was conducted using the UltraVision Quanto Detection System HRP DAB kit (Gene Tech). Kidney tissues were deparaffinized and rehydrated. For antigen retrieval, sections were submerged in citrate buffer $(\mathrm{pH}$ 6.0) at $100{ }^{\circ} \mathrm{C}$ for $30 \mathrm{~min}$. After blocking endogenous peroxidase activity and nonreactive sites, primary rabbit anti-human LRG1 antibody (ATLAS; 1:200) were incubated overnight at $4{ }^{\circ} \mathrm{C}$. Goat-anti rabbit immunoglobulins and diaminobenzidine tetrahydrochloride solution were used to detect antibody binding.

\section{Immunofluorescence staining and co-localization assay}

The paraffin sections were de-paraffinized, antigen retrieval and incubated in blocking serum according to the same method as IHC. After incubation with the primary antibody (rabbit anti-LRG1, ATLAS, dilution 1:50; fluorescein Lotus tetragonolobus lectin, Vector Laboratories, dilution 1:100; biotinylated Dolichos biflorus agglutinin, Vector Laboratories, dilution 1:250; rabbit anti-thiazide- 
Table 1 Demographics and clinical characteristics of patients with lupus nephritis and healthy controls

\begin{tabular}{|c|c|c|c|}
\hline Parameters & lupus nephritis & healthy controls & $\boldsymbol{P}$ value \\
\hline $\mathrm{n}$ & 101 & 21 & - \\
\hline Female, n (\%) & $82(81.2 \%)$ & $14(66.7 \%)$ & $0.14^{\mathrm{a}}$ \\
\hline Age, median (IQR), years & $29.0(24.0-38.0)$ & $31.0(27.5-39.5)$ & $0.15^{\mathrm{b}}$ \\
\hline Mean arterial pressure, mean (SEM), mmHg & $97.8(1.4)$ & $91.7(1.5)$ & $<0.01^{\mathrm{c}}$ \\
\hline LN duration, median (IQR), years & $0.3(0.1-1.4)$ & - & - \\
\hline SLEDAI-2 k, mean (SEM) & $17.8(0.6)$ & - & - \\
\hline Renal SLEDAI, median (IQR) & $12.0(8.0-16.0)$ & - & - \\
\hline Al score, median (IQR) & $5.0(4.0-7.0)$ & - & - \\
\hline $\mathrm{Cl}$ score, median (IQR) & $4.0(3.0-5.0)$ & - & - \\
\hline 24-h urine protein, median (IQR), g & $2.5(1.0-7.0)$ & - & - \\
\hline Hemoglobin, mean (SEM), g/L & $108.5(2.0)$ & - & - \\
\hline Serum albumin, mean (SEM), g/L & $26.9(0.8)$ & - & \\
\hline Serum creatinine, median (IQR), $\mu \mathrm{mol} / \mathrm{L}$ & $70.0(56.0-99.8)$ & - & - \\
\hline Blood urea nitrogen, median (IQR), mmol/L & $6.3(4.5-8.2)$ & - & - \\
\hline Uric acid, median (IQR), $\mu \mathrm{mol} / \mathrm{L}$ & $342.5(273.5-418.8)$ & - & - \\
\hline Blood phosphorus, median (IQR), mmol/L & $1.2(1.1-1.4)$ & - & - \\
\hline Complement 3, median (IQR), g/L & $0.4(0.3-0.6)$ & - & - \\
\hline Complement 4, median (IQR), g/L & $0.07(0.04-0.1)$ & - & - \\
\hline
\end{tabular}

Values are expressed as mean (SEM), median (25-75th percentile) or $\mathrm{n}(\%) .{ }^{\mathrm{a}}$ Chi-square test. ${ }^{\mathrm{b}}$ Mann Whitney $\mathrm{U}$ test. ${ }^{\mathrm{c}} \mathrm{t}$-test.

SLEDAI-2 k, SLE Disease Activity Index 2000; IQR, interquartile range; Al, activity index; Cl, chronicity index

sensitive Nacl cotransporter, Millipore, dilution 1:500) diluted in PBS at $4{ }^{\circ} \mathrm{C}$ overnight, the slides were incubated with the corresponding secondary antibody. For double staining, cells were incubated with the mixture of two primary antibodies (1:50 rabbit anti-LRG1 and 1:25 mouse anti-CD68, CD3, CD11c and CD19) and a mixture of the two secondary antibodies. Finally, all sections were counterstained with DAPI and sealed with 50\% buffered glycerol.

\section{Cell line and culture}

The human renal tubular epithelial cell line HK-2 and Human umbilical vein endothelial cell line HUVEC, were obtained from the Cell Bank of the Chinese Academy of Sciences (Beijing, China). Cells were maintained in RPMI-1640 medium supplemented with $10 \%$ fetal bovine serum and $100 \mathrm{U} / \mathrm{mL}$ penicillin streptomycin and maintained at $37^{\circ} \mathrm{C}$ in a humidified atmosphere containing $5 \% \mathrm{CO} 2$.

\section{Western blot}

Total cell lysates from HK-2 cell lines were extracted with radioimmunoprecipitation (RIPA) assay buffer containing phenylmethane sulfonyl fluoride (PMSF) and protease inhibitors. Primary antibodies against LRG1 (13224-1-AP, Proteintech, 1:1500) and $\beta$-Actin or $\beta$ Tublin (1:2000) and secondary antibody horseradish peroxidase were used.

\section{Evaluation of cell apoptosis}

Cell apoptosis was probed using the FITC Annexin V/PI Apoptosis Detection Kit (AntGene, Wuhan, China) according to the manufacturer's instructions. Evaluation of cell proliferation. The cell counting kit-8 (CCK-8) assay (Promoter, Wuhan, China) was used to evaluate cell proliferation. The absorbance was measured in a microplate reader at $450 \mathrm{~nm}$.

\section{RNA extraction and quantitative real-time PCR (qRT-PCR) analysis}

Total RNA was isolated from cells by the TRIzol reagent (Invitrogen) and was reversely transcribed into cDNA using PrimeScript RT Reagent (Takara, Japan) after RNA quantification. qRT-PCR, was performed on an Applied Biosystems 7500 Real-time PCR System using SYBR Premix Ex Taq Kit (TaKaRa, Dalian, China) following the manufacturer's protocols. All primer sequences were showed in Additional file 1: Table S1.

\section{Statistical analysis}

To show the normal distribution of variables, the Kolmogorov-Smirnov test was used by SPSS 23.0 software. GraphPad Prism 6 and were used for other statistical analysis and visualization. The t-test was used for univariate parametric comparisons. Mann Whitney U test or Kruskal-Wallis test followed by Dunn's multiple comparison test were used for univariate nonparametric 


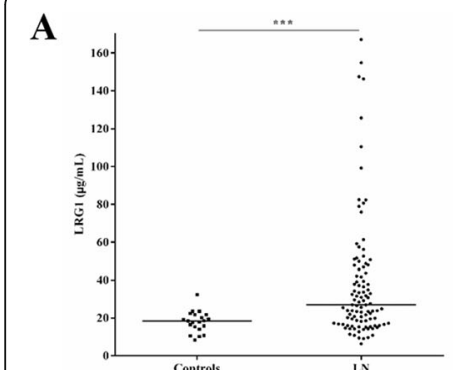

$\mathbf{D}$

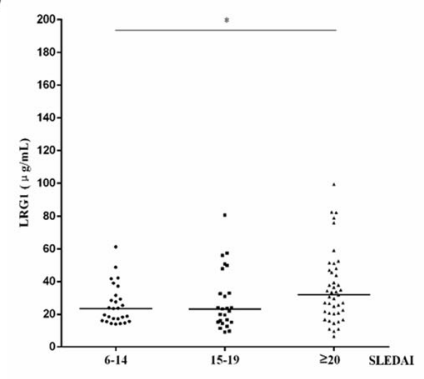

B

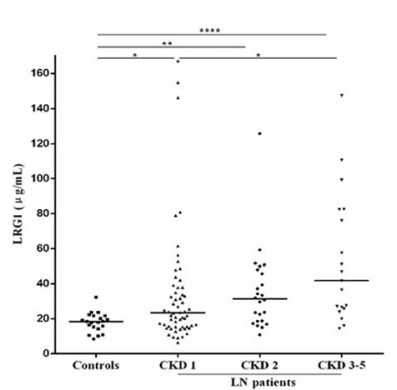

$\mathbf{E}$

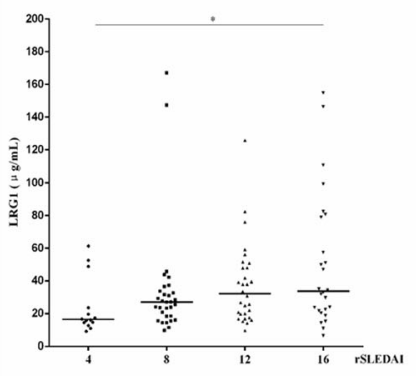

C

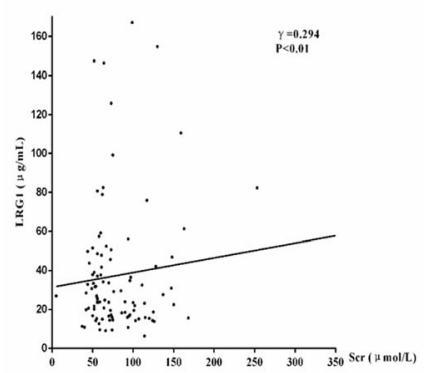

$\mathbf{F}$

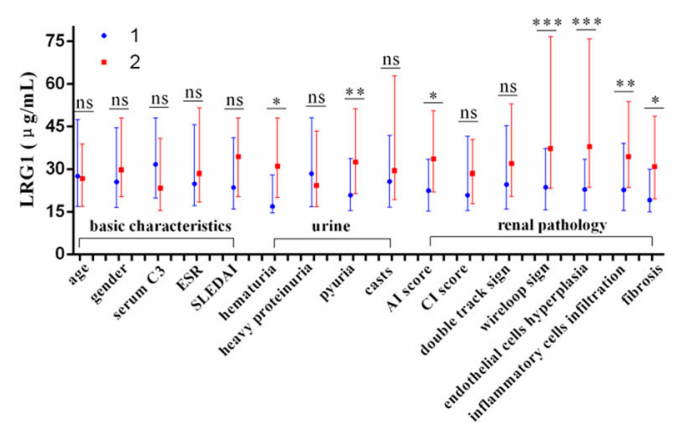

Fig. 1 Plasma leucine-rich alpha-2 glycoprotein 1 (LRG1) levels in lupus nephritis (LN) patients and its correlation to indicators. a Plasma LRG1 levels in LN patients and healthy controls. b Differences in plasma concentrations of LRG1 between different patients with different CKD grades. $\mathbf{c}$ Plasma levels of LRG1 are positively correlated with serum creatinine $(\gamma=0.294, P<0.01)$. $\mathbf{d}$, e Differences in plasma concentrations of $L R G 1$ between different patients with different SLE activity grade (SLEDAI) and renal SLEDAI (rSLEDAI). $\mathbf{f}$ Differences in plasma concentrations of LRG1 between different patients with other different clinical and pathological indicators, 1 and 2 are representative $<$ and $\geq$ median: 29.0 years for age, $5.0 \mathrm{Al}$ score, $4.0 \mathrm{Cl}$ score, 0.4 for complement 3 (C3); female and male for gender; $<$ and $\geq 20$ for SLEDAl; $<20$ and $\geq 20 \mathrm{~mm} / \mathrm{h}$ for erythrocyte sedimentation rate (ESR); - and + for hematuria, heavy proteinuria, pyuria, casts, double track sign, wireloop sign, endothelial cells hyperplasia and fibrosis; light and heavy for inflammatory cell infiltration. Symbols represent individual data points with the median as a horizontal line in Fig. 1a, $\mathrm{b}, \mathrm{d}$ and e. Data are presented as bar graphs with the median and 25-75th percentile of the plasma LRG1 concentrations in Fig. If (ns, not significant; ${ }^{*} P<0.05 ;{ }^{* *} P<0.01 ;{ }^{* * *} P<0.001 ;{ }^{* * *} P<0.0001$ )

comparisons. Spearman's correlation analyses were performed to evaluate the association between nonparametric variables. A two-tailed $P<0.05$ was considered statistically significant.

\section{Results}

\section{Plasma concentrations of LRG1 in HC and patients with} LN

For the included $101 \mathrm{LN}$ patients and $21 \mathrm{HC}$, there was no statistically significant difference in the age or the sex ratio between the two groups (Table 1). pLRG1 levels were significantly elevated in patients with LN compared with those in the $\mathrm{HC}(P<0.001$; Fig. 1a).

\section{Plasma concentrations of LRG1 in patients with LN according to stages of CKD}

All LN patients were divided into 3 groups according to stages of CKD: stage $1(n=58)$, stage $2(n=24)$ and stage $3-5(n=19)$ of CKD. pLRG1 levels were higher in all stage 1 , stage 2 and stage $3-5$ groups than in $\mathrm{HC}$ group $(P<0.05, P<0.01$ and $P<0.0001$, respectively; Fig. $1 \mathrm{~b})$. pLRG1 levels were not significantly different between stage 1 group and stage 2 groups $(P=0.147$; Fig. 1b).
However, pLRG1 levels in stage 3-5 of CKD significantly differed from the stage 1 ( $P<0.05$; Fig. 1b). pLRG1 levels in stage $3-5$ of CKD was not significantly higher than in the stage $2(P=0.121$; Fig. $1 \mathrm{~b})$. And the Spearman's correlation analyses showed that pLRG1 level was weakly positively correlated to serum creatinine $(\gamma=0.294 ; P<$ 0.01; Fig. 1c). All these showed that pLRG1 level had a tendency to increase with stage of CKD.

\section{Plasma concentrations of LRG1 in patients with LN according to disease activity status}

All patients' Systemic Lupus Erythematosus Disease Activity Index (SLEDAI) and renal Systemic Lupus Erythematosus Disease Activity Index (rSLEDAI) scores were calculated to evaluate overall and renal disease activity [31]. All LN patients were divided into a low active group (6-14 scores; $n=29)$, a moderate active group (15-19 scores; $n=27$ ) or a high active group ( $\geq 20$ scores; $n=45$ ) according to their SLEDAI scores. pLRG1 levels were higher in score $\geq 20$ group than in score 614 group $(P=0.043$; Fig. $1 d)$.

The rSLEDAI scores were a sum of four urinary items including hematuria ( $\geq 5$ red blood cells/high-power 


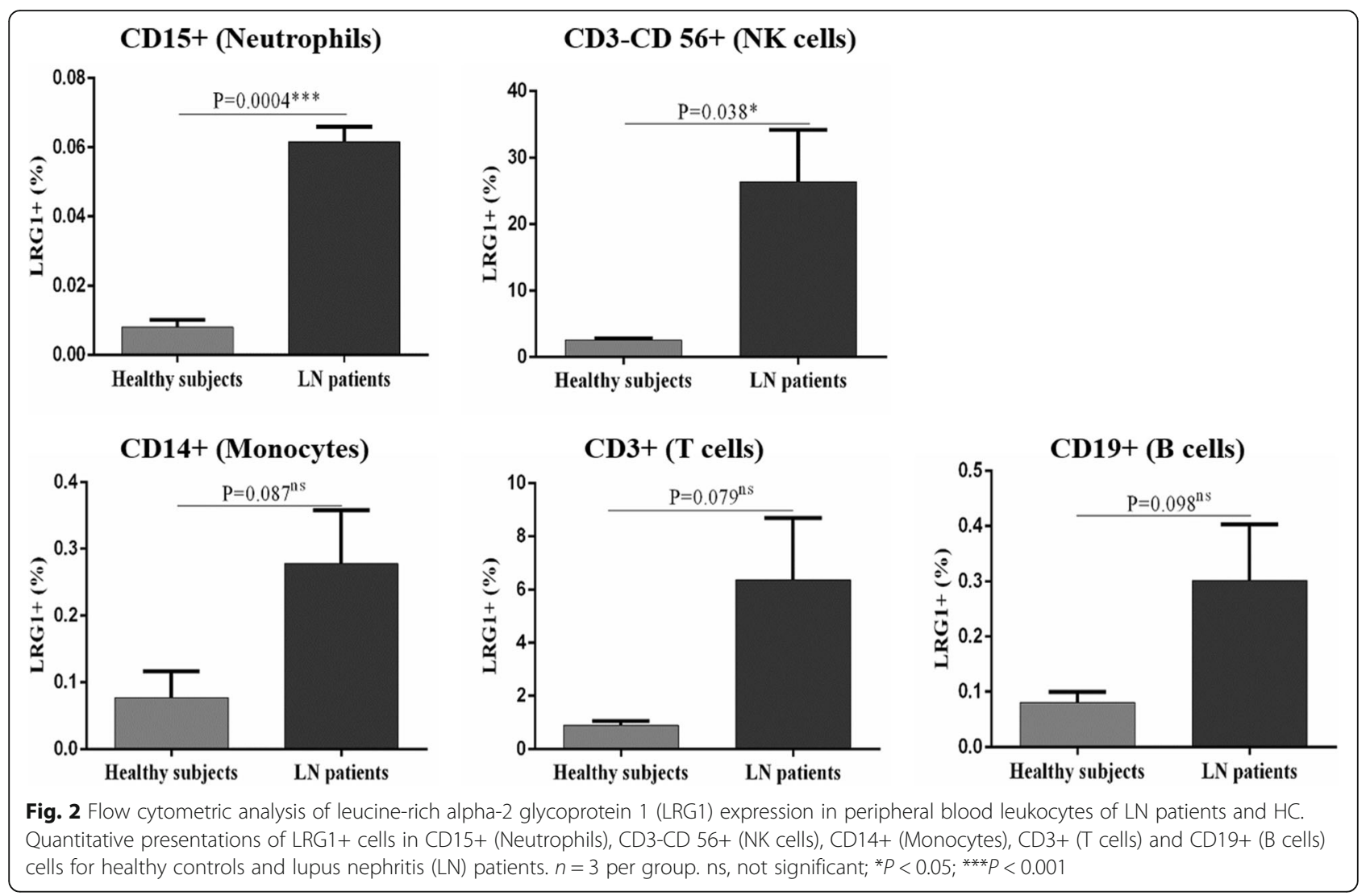

field), proteinuria ( $\geq 0.5 \mathrm{~g} / 24 \mathrm{~h}$ or spot urine protein $/ \mathrm{Cr}$ ratio $>0.5$ ), pyuria ( $\geq 5$ white blood cells/high-power field) and casts (composed of heme, granule, or red blood cells). The scale of each parameter was 0 or 4 , and total rSLEDAI score were $0,4,8,12$, or 16 [31]. pLRG1 levels were higher in score 16 group than in score 4 group $(P=0.019$; Fig. 1e).

\section{Plasma concentrations of LRG1 in patients with LN according to other clinical and pathological characteristics}

All LN patients were respectively divided into number 1 group and number 2 group according to age $(<$ and $\geq$ median: 29.0 years), gender (female and male), SLEDAI $(<$ and $\geq 20)$, hematuria $(-$ and $\geq+)$, heavy proteinuria (and + ), pyuria $(-$ and +$)$, casts $(-$ and +$)$, Activity index (AI) score (< and $\geq$ median: 5$)$, Chronicity index (CI) score (< and $\geq$ median: 4.0 ), serum complement 3 (< and $\geq$ median: 0.4 ), ESR ( $<$ and $\geq 20$ ), double track sign $(-$ and +$)$, wireloop sign $(-$ and +$)$, endothelial cells hyperplasia $(-$ and +$)$, inflammatory cells infiltration (light and heavy) and fibrosis (- and +). pLRG1 levels were higher in several number 2 groups than in number 1 groups for hematuria, pyuria, AI score, wireloop sign, endothelial cells hyperplasia, inflammatory cells infiltration, and fibrosis (all $P<0.05$; Fig. 1f; Additional file 2: Table S2).

\section{LRG1 expression in peripheral blood leukocytes}

To identify the potential sources of LRG1 production, we investigated LRG1 expression in peripheral blood leukocytes (Fig. 2). The result showed that the percentages of LRG1+ cells present in CD15+ and CD3-CD56+ cell populations were higher in patients with $\mathrm{LN}$ when compared with $\mathrm{HC}$ subjects $(P=0.0004$ and $P=0.04$, respectively), but not in CD14+ $(P=0.09), \mathrm{CD} 3+(P=$ $0.079)$ and $C D 19+(P=0.098)$ cell populations. Moreover, large proportions of CD3-CD56+ and CD3+ expressed LRG1 but the percentages of LRG1+ cells in CD15+, CD14+ and CD19+ cell populations were very low $(<1 \%)$ both in LN patients and HC.

Renal expression of LRG1 was higher in patients with LN LRG1 expression in the LN patients and HC was measured by using immunohistochemistry. As shown, LRG1 was mainly expressed at some tubes; at renal interstitial and glomerulus, there was only dotted expression of LRG1. LRG1 expression in the LN patients group was significantly higher than in the $\mathrm{HC}$ group $(P<0.01$; Fig. 3 and Additional file 3: Figure S1). 

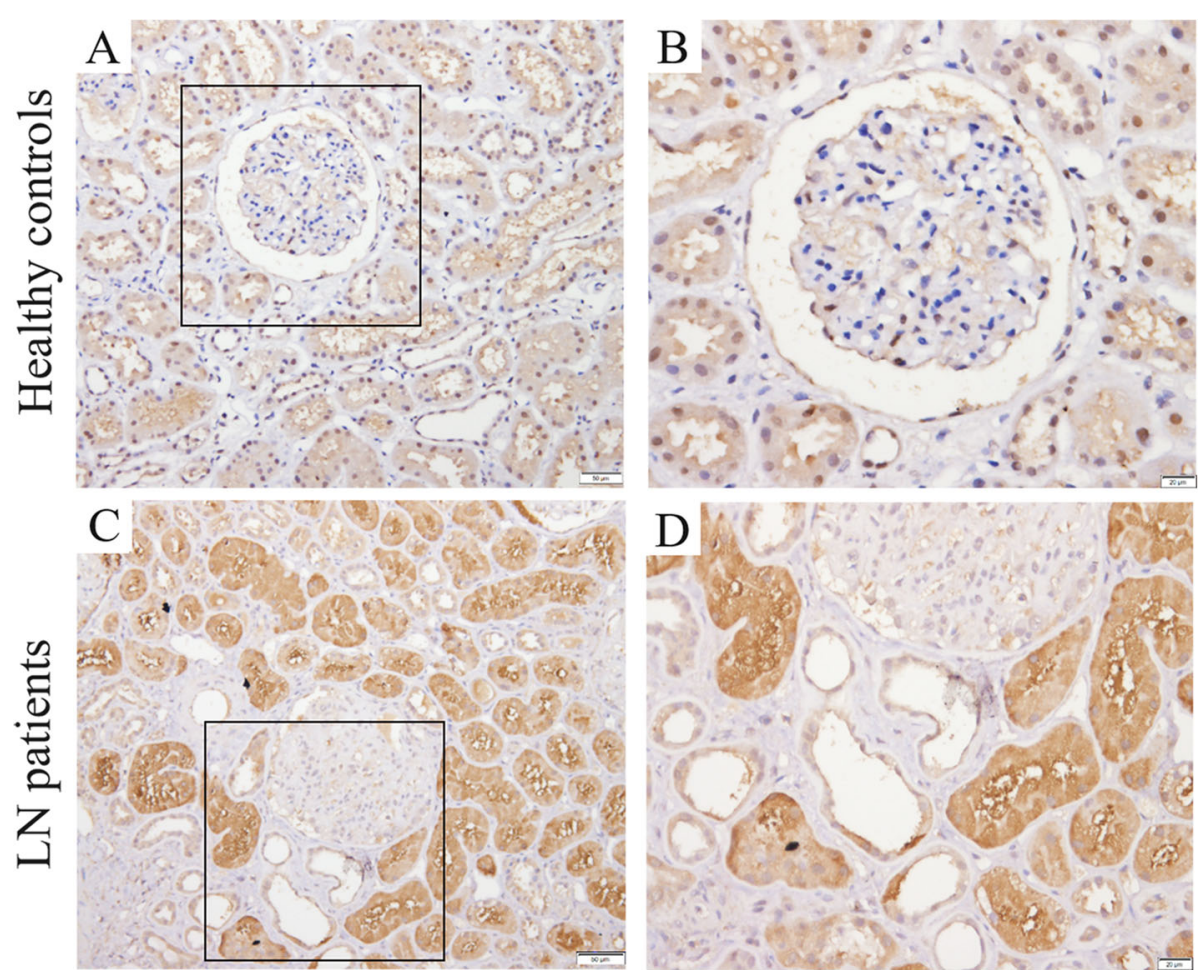

Fig. 3 Renal cortical expression of leucine-rich alpha-2 glycoprotein 1 (LRG1) in human kidney biopsies. Representative photomicrographs of LRG1 staining in human renal cortical tissue from normal subjects (a and $\mathbf{b}$ ), lupus nephritis (LN) patients (c and $\mathbf{d}$ ). Hematoxylin stain; original magnification, $\times 200$ (A and C, Scale bars, $50 \mu \mathrm{m}) ; \times 400(\mathbf{b}$ and $\mathbf{d}$, Scale bars, $20 \mu \mathrm{m})$

\section{LRG1 was located at proximal tubule and some inflammatory cells in kidney}

It was shown that LRG1 was expressed at proximal tubule (marker: Lotus tetragonolobus lectin, LTL) but not at distal tubule (marker: Nacl cotransporter, NCC) and collection tube (marker: Dolichos biflorus agglutinin, DBA) by immunofluorescence staining for continuous kidney section (Fig. 4a). Immunofluorescence colocalization staining showed that cells of CD68+ (macrophages), CD3+ ( $\mathrm{T}$ cells) and CD19+ (B cells) co-dyed with LRG1 and cells of CD11c + (dendritic cells) did not co-dye with LRG1 (Fig. 4b).

\section{IL-1 $\beta$ and IL-6 induced HK-2 cells to produce LRG1}

To determine whether the inflammatory factors could induce the production of LRG1, we stimulated HK-2 cells by IL-1 $\beta$, IL-6, TNF- $\alpha$ and IFN- $\gamma$ for $8 \mathrm{~h}$. Western blot showed IL- $1 \beta$ and IL- 6 could induce expression of LRG1 in HK-2 cells (Fig. 5a, b).

Recombinant human LRG1 (rhLRG1) stimulating induced proliferation, inhibited late apoptosis, and regulated inflammation in HUVEC cells

Endothelial cell proliferation was one of the most vital pathological changes of LN. $500 \mathrm{ng} / \mathrm{mL}$ rhLRG1 was used to stimulate HUVEC cell line. The cell growth curves of 24 and $48 \mathrm{~h}$, as assessed by the CCK- 8 method, indicated that the growth rate was higher in the rhLRG1 stimulating group than control group (Fig. 5d). As shown in Fig. 5c, the late apoptotic rate was decreased, but the early apoptotic rate was not significantly different in the LRG1 stimulating ( $8 \mathrm{~h})$ group compared with control group (Fig. 5c). Besides, LRG1 induced mRNA expression of Bcl-2 (Fig. 5e). These results indicated that LRG1 exerted more prominent pro-proliferative and anti-apoptotic effects on the HUVECs. Stimulation of rhLRG1 on HUVEC decreased the mRNA expression levels of IL-6, IL-4, IL-23, CCL20 and CXCL2, and increased that of CCL5 (Fig. 5e). It might be a multiple regulatory factor in inflammation.

\section{Discussion}

This is the first LRG1 study in the population of biopsyproven LN so far. In this study, we found that in patients with LN, LRG1 was expressed in plasma, several white blood cells of peripheral blood, at proximal tubule and several inflammatory cells of kidney. And we also examined its potential effects on kidney.

In plasma, level of LRG1 might be a good indicator of renal function and renal disease activity of LN. pLRG1 was positively correlated with serum creatinine levels and stages of CKD. It was reported that high level of 


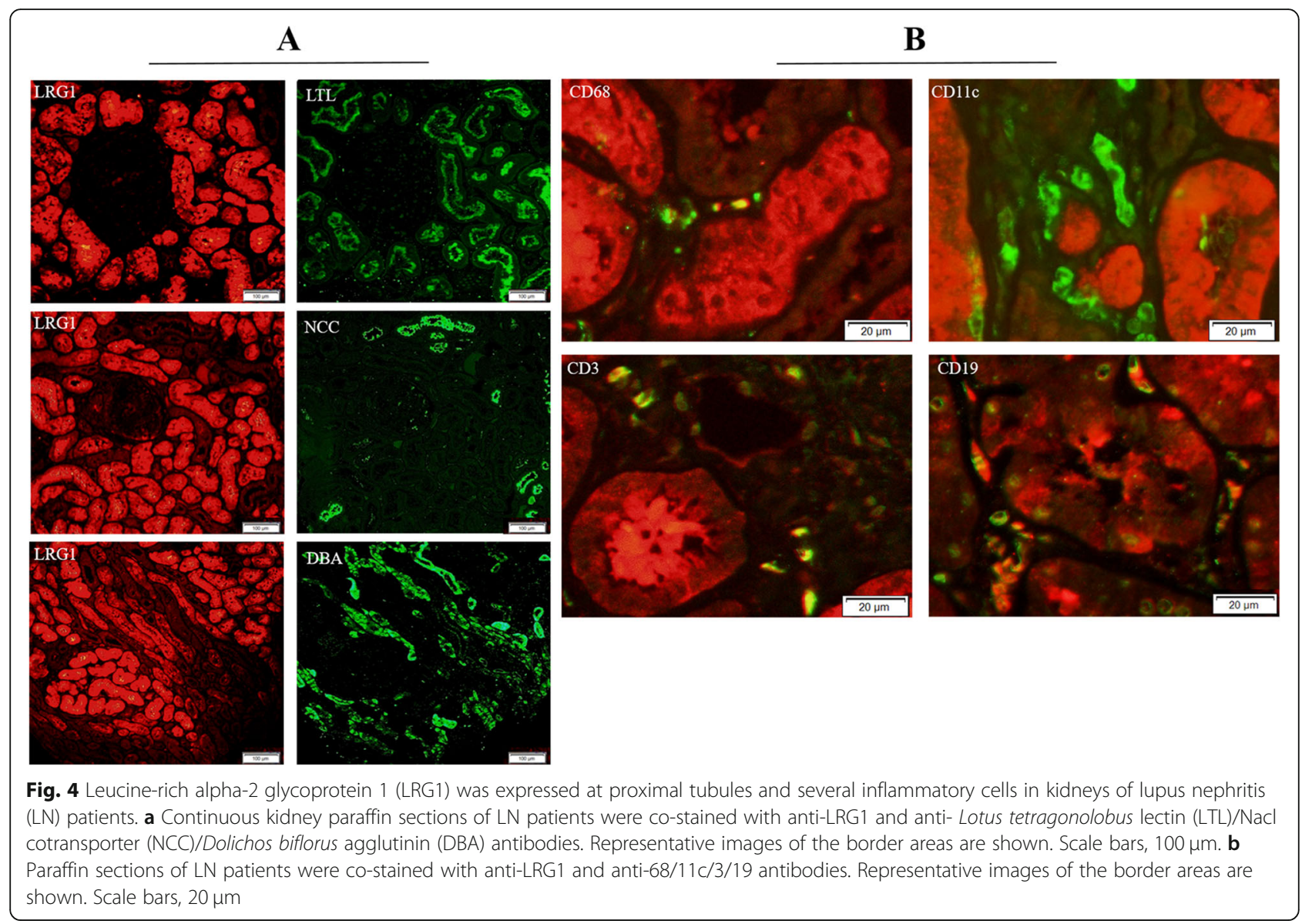

serum LRG1 pointed to a subclinical kidney insufficiency in classical galactosemic patients by proteomics methods [27]. Furthermore, fluctuations of pLRG1 levels were found to reflect renal function in LN patients, thus potentially serving as a helpful biomarker in the clinical follow-up. Meanwhile, pLRG1 was a biomarker of renal disease activity of LN. In patients with highest rSLEDAI score, level of pLRG1 was higher than that in lowest rSLEDAI score. LRG1 was reported to be involved in inflammatory and autoimmune diseases. In active LN, the inflammatory and autoimmune reactions were more serious. In previous study, serum LRG1 concentrations correlated with disease activity in SLE, rheumatoid arthritis, Crohn's disease, ulcerative colitis and adult-onset Still's disease [12, 20, 22, 24, 32].

It was reported that serum LRG1 was elevated in patients with SLE and correlated with disease activity [24]. Similarly, we found LN patients with higher SLEDAI had higher pLRG1 concentrations. Differently, in our study, we included biopsy-proven LN patients instead of SLE patients. We found pLRG1 was elevated in LN patients compared to $\mathrm{HC}$ and might be a good indicator of renal function and renal disease activity of LN.
One of the strengths of our study was the examination of pLRG1's ability to predict renal pathology. Higher levels of pLRG1 existed in patients who had wireloop sign, heavy inflammatory cells infiltration and fibrosis in the kidneys. Wireloop sign characterized by a large number of immunocomplex deposited under the endothelium, and heavy infiltration of inflammatory cells indicated severe inflammatory and immune reactions in kidney, which was consistent with the association between pLRG1 and rSLEDAI above. Fibrosis in renal tubular interstitium reflected chronic injury and loss of function of kidney, which was also consistent with the association between pLRG1 and renal function above. Recently, Lee et al. revealed that urinary LRG1 was a potential biomarker for renal tubular injury in mouse albumin overload model [29]. Therefore, LRG1 might be associated with renal inflammation, immunity, fibrosis and injury.

In addition, we revealed that pLRG1 elevated in patients with hyperplasia of renal endothelial cells. And the stimulation of rhLRG1 induced proliferation of HUVEC cell line. This might result from the following two possible reasons. On the one hand, LRG1 might be involved in renal inflammation and deposition of immune 


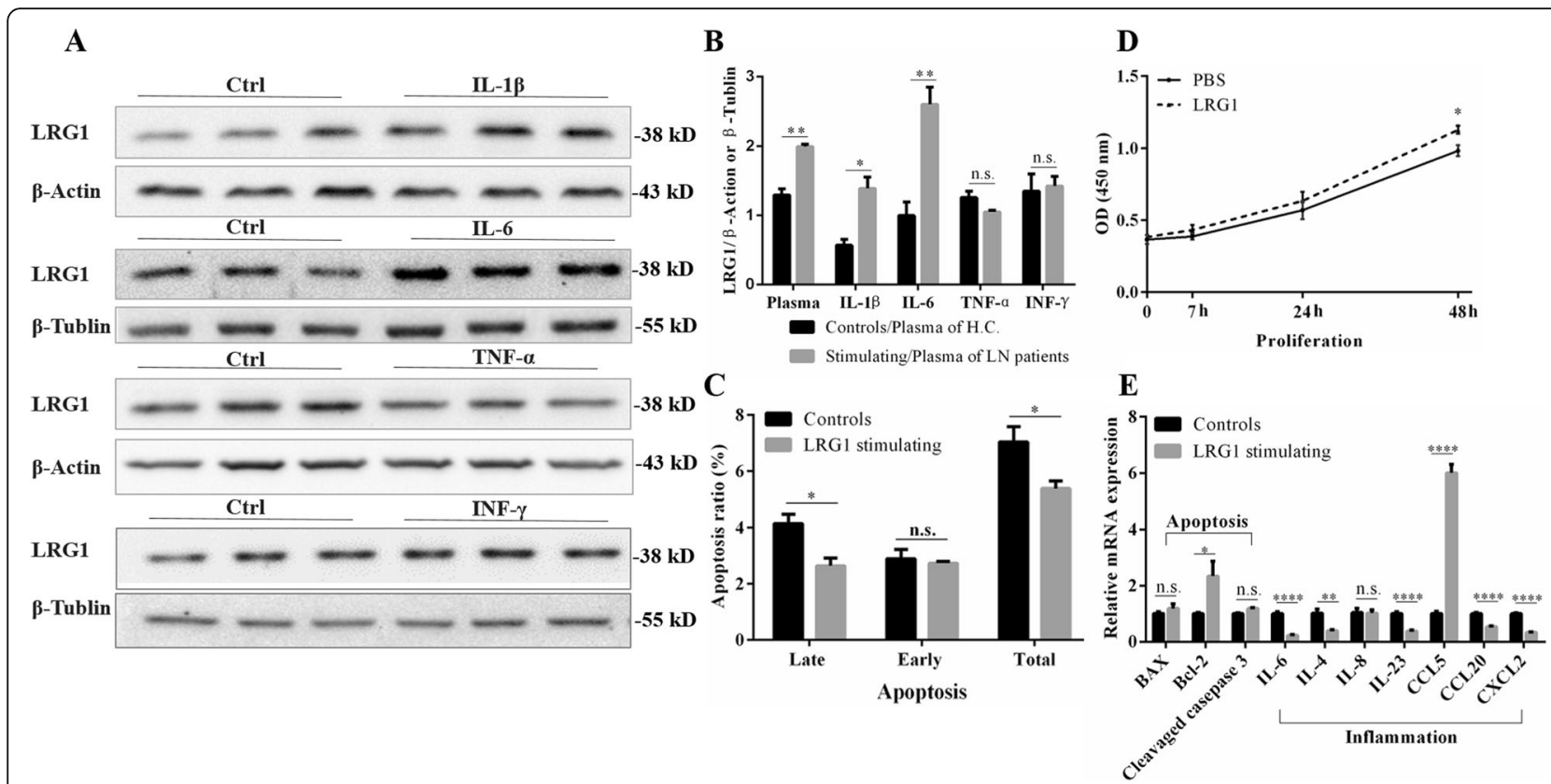

Fig. 5 Leucine-rich alpha-2 glycoprotein 1 (LRG1) could be induced by proinflammatory cytokines in HK-2 cell line and its effects on HUVEC cell line. $\mathbf{a}, \mathbf{b}$ The expressions of LRG1 were analysed by western blot in HK-2 cells stimulated with $20 \mathrm{ng} / \mathrm{mL} \mathrm{IL}-1 \beta$, IL- 6 , TNF- $\alpha$ and INF- $\gamma$ for $8 \mathrm{~h}$ ( $\mathrm{n}=$ 3). Analyses were performed by Student's t test. c HUVEC cells stimulated by $500 \mathrm{ng} / \mathrm{mL}$ rhLRG1 for $8 \mathrm{~h}$ were double stained with FITC-conjugated anti-Annexin Vantibody and PI, followed by flowcytometry analysis for cell apoptosis. $\mathbf{d}$ CCK-8 assay was performed to assess cell proliferation in HUVEC cell line. e HUVEC cell line was stimulated by $500 \mathrm{ng} / \mathrm{mL}$ rhLRG1 for $24 \mathrm{~h}$. The expression of mRNA was analyzed by real-time RT-PCR and GAPDH was used as an internal control for grayscale analysis. Data are shown as mean \pm SEM. c-e analyses were controls groups vs. $500 \mathrm{ng} / \mathrm{mL}$ LRG1 stimulating groups performed by Student's t test. n.S., not significant. ${ }^{*} P<0.05,{ }^{* *} P<0.01,{ }^{* * *} P<0.001,{ }^{* * * *} P<0.0001$. LRG1: leucine-rich a2glycoprotein 1; IL: Interleukin; TNF: Tumor necrosis factor; INF: Interferon; CCL: chemokine (C-C motif) ligand; CXCL: Chemokine (C-X-C Motif) Ligand 1

complexes, causing injury and further hyperplasia of endothelial cells. On the other hand, LRG1 was reported mitogenic to endothelial cells by modulating endothelial TGF- $\beta$ signaling [30]. Hypercellularity of endothelial cells was one of basic pathological regenerations after injury in the glomeruli, which would further cause hematuria, proteinuria and decrease in glomerular filtration rate.

In our study, level of pLRG1 was elevated in LN patients compared with that in HC. The possible causes were as follows. First, we found in neutrophils and NK cells of peripheral blood, the LRG1 expression increased in LN patients compared to that in HC. Second, as a secretory protein, LRG1 was mainly expressed at proximal tubule. IHC showed the expression of LRG1 increased in kidney tubules of LN patients. Moreover, several inflammatory cells including macrophages, $\mathrm{T}$ cells and B cells of kidney could also expressed LRG1. So the secretion from kidney of LN patients might be increased.

In kidney, the expression of LRG1 also increased in LN patients. And the expression of LRG1 was positive in proximal tubule, and negative in distal tubule or collecting tube. Besides, some inflammatory cells infiltrated in glomerulus and renal interstitium, including macrophage, $\mathrm{T}$ cell and B cell, could also express LRG1. LRG1 could be induced by plasma of LN patients in HK-2 cell line. In order to determine whether proinflammatory cytokines might promote the production of LRG1, we chose IL- $1 \beta$, IL- 6 , TNF- $\alpha$ and INF- $\gamma$ to directly stimulate HK-2 cell line because LRG1 was expressed mainly at proximal tubule. It was reported that these four cytokines increased in LN and were important pathogenic factors. We found LRG1 could be induced by IL-1 $\beta$ and IL-6, but not TNF- $\alpha$ and INF- $\gamma$.

By combined with Figs. 2 and 3, we found in the fibrotic renal tissue, the expression of LRG1 was reduced. Because LRG1 was mainly and extensively expressed at the proximal tubule and proximal tubule was destroyed in the fibrotic tissue. However, several inflammatory cells, including macrophages, $\mathrm{T}$ cells and B cells, could also express LRG1. But, the total amount of LRG1 expression was reduced. Figure if showed that plasmic LRG1 level was higher in LN patients with renal fibrosis. The opposite conclusion might be explained by the following reasons: Firstly, Fig. If was the result of LRG1 level in plasma, but not kidney; Secondly, in the process of renal fibrosis, the destroyed proximal tubules might 
release LRG1 into the blood. However, the exact reason needs further studies.

Furthermore, we revealed that LRG1 might be associated with inflammation, proliferation and apoptosis of the endothelial cell. It could induce chemokine (C-C motif) ligand 5 (CCL5), but reduce CCL20, CXCL2, IL4, IL-6 and IL-23 in HUVEC cell line. pLRG1 was elevated in patients with high renal disease activity and LRG1 could be induced by some inflammatory cytokines. Meanwhile, the stimulation of LRG1 could increase CCL5, but reduce some other cytokines. LRG1 might have bidirectional regulation of inflammation.

The reduced proinflammatory cytokines IL-6, IL-23, CCL20 and CXCL12 played antiinflammatory role in LN. IL-6 is a lymphokine produced by activated T cells and fibroblasts, which can make B cell precursors become antibody producing cells. In collaboration with colony stimulating factor, IL- 6 can promote the growth and differentiation of original bone marrow-derived cells and enhance the lysis function of natural killer cells [33]. IL-23 is released from antigen presenting cells and induces expansion of Th17 cells and is necessary for their maintenance, thus forming the IL-23/IL-17 axis [34]. CCL20 is a chemokine of CC subfamily, which directly participates in the directional migration of dendritic cells and $\mathrm{T}$ cells through its ligand CCR6. CXCL12 is a classic inflammatory chemokine and can be secreted by a variety of cells, including lymphocytes, monocytes, and endothelial cells, to bind to its receptor, CXCR4. In glomerulonephritis, CXCR4 is overexpressed in parietal epithelial cells of the kidney, triggering their migration into the glomerular tuft where they form hyperplastic lesions [35]. LRG1 might participate in the inflammatory response by reducing these proinflammatory factors.

In HUVEC cell line, we found the stimulation of rhLRG1 not only promoted cell proliferation but also inhibited apoptosis, mainly late apoptosis. It was well known that inadequate apoptosis and excessive apoptosis were both harmful to LN, such as inadequate apoptosis of lymphocytes targeting autoantigens and excessive apoptosis of renal tubular cell. In fact, for endothelial cells, apoptosis and hyperplasia were both its reactions to injury. LRG1 inducing proliferation and reducing apoptosis of endothelial cells might together lead to proliferation of endothelial cells, which influenced renal structural and functional integrity. In this respect, LRG1 might be might be involved in pathological changes of kidney to injury.

However, pLRG1 did not correlate well with proteinuria, which is another important marker of LN severity. The possible reasons are as follows: Firstly, proteinuria is a relative early manifestation of $\mathrm{LN}$, and renal insufficiency is a more serious manifestation of the disease progression. Proteinuria and renal function are not necessarily parallel, and their risk factors are not identical. Secondly, in our study, we found LRG1 had more effect on proliferation of endothelial cells, which might influence renal function. Proteinuria was effected more on damage to podocytes and charge barrier. However, the exact mechanism needs our further research on lupus and LRG1.

Our study has several limitations. First, the sample size of LN biopsies was relatively modest. Second, due to the cross-sectional design, the serial change in PLRG level according to the change in the progression or relief of LN and the association between pLRG1 and prognosis of LN could not be defined. Further large-sized, longitudinal studies were warranted.

\section{Conclusions}

This work demonstrates that LRG1 are promising LN biomarkers. LRG1 was widely expressed in peripheral blood and kidney of LN. The level of plasma LRG1 was elevated in LN patients as compared to HC. Plasmic expression levels of LRG1 correlate positively with renal function and disease activity, and reflect specific pathologic lesions in the kidneys of patients with LN. It may also be involved in inflammation, proliferation and apoptosis of endothelial cells. Therefore, we suggest that this protein should be regularly checked in LN patients. However, this is the first LRG1 study in populations of $\mathrm{LN}$, and further studies is needed to assess its clinical utility and functions of the disease.

\section{Supplementary information}

Supplementary information accompanies this paper at https://doi.org/10. 1186/s12882-020-01782-0.

Additional file 1: Table S1. Primers for quantitative real time reverse transcription polymerase chain reaction.

Additional file 2: Table S2. Differences in plasma concentrations of LRG1 between different patients with other different clinical and pathological indicators (The explanation of the Fig. 1f).

Additional file 3: Figure S1. $L R G 1$ was stained in kidney of $L N$ patients.

\begin{abstract}
Abbreviations
LRG1: Leucine-rich a2-glycoprotein-1; LN: Lupus nephritis; pLRG1: plasma LRG1; HC: Healthy controls; SLE: Systemic lupus erythematosus; SLEDAI-2 k: SLE Disease Activity Index 2000; Al: Activity index; Cl: Chronicity index; IL: Interleukin; TNF: Tumor necrosis factor; INF: Interferon; CCL: Chemokine (CC motif) ligand; CXCL: Chemokine (C-X-C Motif) Ligand 1
\end{abstract}

\section{Acknowledgements}

Not applicable.

\section{Authors' contributions}

$X G$ and GSW conceived and designed the study. YY performed the procedures, statistical analysis and composed the manuscript. LR, CYC, LTT, DW, LYQ contributed to procedures and statistical analysis. All authors read the manuscript and approved the final version. 


\section{Funding}

This project was supported by Major Research plan of the National Natural Science Foundation of China (Grant no. 91742204); International (regional) cooperation and exchange projects (NSFC-DFG, Grant no. 81761138041), National Natural Science Foundation of China (Grants no. 81470948, 81670633, 81570667), National key research and development program (Grant no. 2016YFC0906103) and The National Key Technology R\&D Program (Grants no. 2018YFC1314003-1, 2015BAl12B07). The funding bodies had no role in the design and conduct of the study; collection, management, analysis, and interpretation of the data; preparation, review, or approval of the manuscript; and decision to submit the manuscript for publication.

\section{Availability of data and materials}

The datasets used and analysed during the current study are available from the corresponding author on reasonable request.

\section{Ethics approval and consent to participate}

The study was conducted in accordance with the Declaration of Helsinki, and the protocol was approved by the Ethical Committee of Tongji Hospital, which is affiliated with Tongji Medical College, Huazhong University of Science and Technology (Project No. TJ-IRB20181106). These patients have signed informed consent at the time of kidney biopsy, agreeing to use the residual specimens of kidney and related materials for further scientific researches. We conducted a retrospective study to collect relevant clinical data of patients, so verbal informed consent was obtained from these participants and was approved by the ethics committee.

\section{Consent for publication}

Not applicable.

\section{Competing interests}

The authors declare that they have no competing interests.

\section{Received: 20 September 2019 Accepted: 23 March 2020}

\section{Published online: 06 April 2020}

\section{References}

1. Tsokos GC. Systemic lupus erythematosus. N Engl J Med. 2011;365(22):211021.

2. Davidson A, Bethunaickan R, Berthier C, Sahu R, Zhang W, Kretzler M. Molecular studies of lupus nephritis kidneys. Immunol Res. 2015;63(1-3): 187-96.

3. Ocampo-Piraquive V, Nieto-Aristizabal I, Canas CA, Tobon GJ. Mortality in systemic lupus erythematosus: causes, predictors and interventions. Expert Rev Clin Immunol. 2018;14(12):1043-1053.

4. Podolska MJ, Biermann MH, Maueroder C, Hahn J, Herrmann M. Inflammatory etiopathogenesis of systemic lupus erythematosus: an update. J Inflamm Res. 2015:8:161-71.

5. Yap DY, Yung S, Chan TM. Lupus nephritis: an update on treatments and pathogenesis. Nephrology (Carlton). 2018;23(Suppl 4):80-3.

6. Alarcon GS, McGwin G Jr, Petri M, Reveille JD, Ramsey-Goldman R, Kimberly RP. Baseline characteristics of a multiethnic lupus cohort: PROFILE. Lupus. 2002;11(2):95-101.

7. Kasitanon N, Magder LS, Petri M. Predictors of survival in systemic lupus erythematosus. Medicine. 2006;85(3):147-56.

8. de Zubiria SA, Herrera-Diaz C. Lupus nephritis: an overview of recent findings. Autoimmune Diseases. 2012;2012:849684.

9. Hogan J, Appel GB. Update on the treatment of lupus nephritis. Curr Opin Nephrol Hypertens. 2013;22(2):224-30.

10. Haupt H, Baudner S. Isolation and characterization of an unknown, leucinerich 3.1-S-alpha2-glycoprotein from human serum (author's transl). HoppeSeyler's Zeitschrift fur physiologische Chemie. 1977;358(6):639-46.

11. Shirai R, Hirano F, Ohkura N, Ikeda K, Inoue S. Up-regulation of the expression of leucine-rich alpha(2)-glycoprotein in hepatocytes by the mediators of acute-phase response. Biochem Biophys Res Commun. 2009; 382(4):776-9.

12. Serada S, Fujimoto $M$, Terabe $F$, lijima $H$, Shinzaki S, Matsuzaki S, Ohkawara T, Nezu R, Nakajima S, Kobayashi T, et al. Serum leucine-rich alpha-2 glycoprotein is a disease activity biomarker in ulcerative colitis. Inflamm Bowel Dis. 2012;18(11):2169-79.
13. O'Donnell LC, Druhan LJ, Avalos BR. Molecular characterization and expression analysis of leucine-rich alpha2-glycoprotein, a novel marker of granulocytic differentiation. J Leukoc Biol. 2002;72(3):478-85.

14. Zhang H, Cao J, Li L, Liu Y, Zhao H, Li N, Li B, Zhang A, Huang H, Chen S, et al. Identification of urine protein biomarkers with the potential for early detection of lung cancer. Sci Rep. 2015:5:11805.

15. Chen Y, Azman SN, Kerishnan JP, Zain RB, Chen YN, Wong YL, Gopinath SC. Identification of host-immune response protein candidates in the sera of human oral squamous cell carcinoma patients. PLoS One. 2014;9(10): e109012.

16. Andersen JD, Boylan $\mathrm{KL}$, Jemmerson R, Geller MA, Misemer B, Harrington KM, Weivoda S, Witthuhn BA, Argenta P, Vogel RI, et al. Leucine-rich alpha2-glycoprotein-1 is upregulated in sera and tumors of ovarian cancer patients. J Ovarian Res. 2010;3:21

17. Capello M, Bantis LE, Scelo G, Zhao Y, Li P, Dhillon DS, Patel NJ, Kundnani $D L$, Wang $H$, Abbruzzese $J$, et al. Sequential Validation of Blood-Based Protein Biomarker Candidates for Early-Stage Pancreatic Cancer. Journal of the National Cancer Institute. 2017;109(4):djw266. https://doi.org/10.1093/ jnci/djw266.

18. Yamamoto M, Takahashi T, Serada S, Sugase T, Tanaka K, Miyazaki Y, Makino T, Kurokawa Y, Yamasaki M, Nakajima K, et al. Overexpression of leucine-rich alpha2-glycoprotein-1 is a prognostic marker and enhances tumor migration in gastric cancer. Cancer Sci. 2017;108(10):2052-60.

19. Salo M, Roth $B$, Stenstrom $P$, Arnbjornsson $E$, Ohlsson B. Urinary biomarkers in pediatric appendicitis. Pediatr Surg Int. 2016;32(8):795-804.

20. Ha YJ, Kang EJ, Lee SW, Lee SK, Park YB, Song JS, Choi ST. Usefulness of serum leucine-rich alpha-2 glycoprotein as a disease activity biomarker in patients with rheumatoid arthritis. J Korean Med Sci. 2014:29(9):1199-204.

21. Fujimoto M, Serada S, Suzuki K, Nishikawa A, Ogata A, Nanki T, Hattori K, Kohsaka H, Miyasaka N, Takeuchi T, et al. Leucine-rich alpha2 -glycoprotein as a potential biomarker for joint inflammation during anti-interleukin-6 biologic therapy in rheumatoid arthritis. Arthritis Rheumatol. 2015:67(8): 2056-60.

22. Ha YJ, Kang EJ, Lee SW, Park YB, Lee SK, Song JS, Choi ST. Serum leucinerich alpha2-glycoprotein is a useful biomarker for monitoring disease activity in patients with adult-onset Still's disease. Scand J Rheumatol. 2015; 44(5):399-403.

23. Honda H, Fujimoto M, Miyamoto S, Ishikawa N, Serada S, Hattori N, Nomura S, Kohno N, Yokoyama A, Naka T. Sputum Leucine-rich Alpha-2 glycoprotein as a marker of airway inflammation in asthma. PLoS One. 2016;11(9): e0162672.

24. Ahn SS, Park Y, Jung SM, Song JJ, Park YB, Lee SW. Serum leucine-rich alpha2-glycoprotein is elevated in patients with systemic lupus erythematosus and correlates with disease activity. Clin Chim Acta. 2018; 486:253-8.

25. Glorieux G, Mullen W, Duranton F, Filip S, Gayrard N, Husi H, Schepers E, Neirynck N, Schanstra JP, Jankowski J, et al. New insights in molecular mechanisms involved in chronic kidney disease using high-resolution plasma proteome analysis. Nephrol Dial Transplant. 2015:30(11):1842-52.

26. Hashida T, Nakada TA, Satoh M, Tomita K, Kawaguchi R, Nomura F, Oda S. Proteome analysis of hemofilter adsorbates to identify novel substances of sepsis: a pilot study. J Artif Organs. 2017;20(2):132-7.

27. Staubach S, Pekmez M, Hanisch FG. Differential proteomics of urinary exovesicles from classical Galactosemic patients reveals subclinical kidney insufficiency. J Proteome Res. 2016;15(6):1754-61.

28. Suresh CP, Saha A, Kaur M, Kumar R, Dubey NK, Basak T, Tanwar VS, Bhardwaj G, Sengupta S, Batra W, et al. Differentially expressed urinary biomarkers in children withplasma. Clin Exp Nephrol. 2016;20(2):273-83.

29. Lee H, Fujimoto M, Ohkawara T, Honda H, Serada S, Terada Y, Naka T. Leucine rich alpha-2 glycoprotein is a potential urinary biomarker for renal tubular injury. Biochem Biophys Res Commun. 2018;498(4):1045-51.

30. Wang X, Abraham S, McKenzie JAG, Jeffs N, Swire M, Tripathi VB, Luhmann UFO, Lange CAK, Zhai Z, Arthur HM, et al. LRG1 promotes angiogenesis by modulating endothelial TGF-beta signalling. Nature. 2013:499(7458):306-11.

31. Gladman DD, Ibanez D, Urowitz MB. Systemic lupus erythematosus disease activity index 2000. J Rheumatol. 2002;29(2):288-91.

32. Serada S, Fujimoto M, Ogata A, Terabe F, Hirano T, lijima H, Shinzaki S, Nishikawa T, Ohkawara T, Iwahori K, et al. iTRAQ-based proteomic identification of leucine-rich alpha-2 glycoprotein as a novel inflammatory biomarker in autoimmune diseases. Ann Rheum Dis. 2010;69(4):770-4. 
33. Kaur S, Bansal Y, Kumar R, Bansal G. A panoramic review of IL-6: Structure, pathophysiological roles and inhibitors. Bioorganic \& medicinal chemistry. 2020;28(5):115327. https://doi.org/10.1016/j.bmc.2020.115327.

34. Langrish $\mathrm{CL}$, Chen Y, Blumenschein WM, Mattson J, Basham B, Sedgwick JD, McClanahan T, Kastelein RA, Cua DJ. IL-23 drives a pathogenic T cell population that induces autoimmune inflammation. J Exp Med. 2005;201(2): 233-40

35. Garcia-Cuesta EM, Santiago CA, Vallejo-Diaz J, Juarranz Y, Rodriguez-Frade JM, Mellado M. The role of the CXCL12/CXCR4/ACKR3 Axis in autoimmune diseases. Front Endocrinol (Lausanne). 2019;10:585.

\section{Publisher's Note}

Springer Nature remains neutral with regard to jurisdictional claims in published maps and institutional affiliations.

Ready to submit your research? Choose BMC and benefit from:

- fast, convenient online submission

- thorough peer review by experienced researchers in your field

- rapid publication on acceptance

- support for research data, including large and complex data types

- gold Open Access which fosters wider collaboration and increased citations

- maximum visibility for your research: over $100 \mathrm{M}$ website views per year

At $\mathrm{BMC}$, research is always in progress.

Learn more biomedcentral.com/submissions 